\title{
Overcoming Therapeutic Inertia to Reduce the Risk of COPD Exacerbations: Four Action Points for Healthcare Professionals
}

\author{
Dave Singh' \\ Steve Holmes ${ }^{2}$ \\ Claire Adams $\mathbb{( D}^{3}$ \\ Mona Bafadhel (iD ${ }^{4}$ \\ John R Hurst (iD ${ }^{5}$
}

'Medicines Evaluation Unit, University of Manchester, Manchester University NHS Foundation Hospitals Trust, Manchester, UK; ${ }^{2}$ The Park Medical Practice, Shepton Mallet, UK; ${ }^{3}$ Tees Valley Clinical Commissioning Group, Middlesbrough, UK; ${ }^{4}$ Nuffield Department Clinical Medicine, University of Oxford, Oxford, UK; ${ }^{5}$ UCL Respiratory, University College London, London, UK
Correspondence: John R Hurst

UCL Respiratory, Royal Free Campus,

University College London, London,

NW3 2QG, UK

Tel +442074726260

Email j.hurst@ucl.ac.uk
Background: Therapeutic inertia, defined as failure to escalate or initiate adequate therapy when treatment goals are not met, contributes to poor management of COPD exacerbations. Methods: A multidisciplinary panel of five expert clinicians actively managing COPD and representative of UK practice developed action points to reduce exacerbation risk, based on evidence, clinical expertise, and experience. The action points are applicable despite changing circumstances (eg, virtual clinics). The panel agreed areas where further evidence is needed.

Results: The four action points were (1) an experienced HCP, such as a GP or member of the multi-professional COPD team should review patients within one month of every exacerbation that requires oral steroids, antibiotics, or hospitalization to address modifiable risk factors, optimize non-pharmacological measures, and evaluate pharmacological therapy. (2) Presenting to hospital with an exacerbation defines an important window of opportunity to reduce the risk of further exacerbations. Follow-up by a GP, or member of the multiprofessional specialist COPD team within one month of discharge with a full management review and appropriate escalation of pharmacological treatment is essential. (3) Healthcare professionals (HCPs) in all healthcare settings should be able to recognize COPD exacerbations, refer as appropriate and document the episode accurately in medical records across service boundaries. HCPs should support patients to recognize and report exacerbations. (4) HCPs should intervene proactively based on risk assessments, disease activity and any treatable traits at or as soon as possible after diagnosis and annually thereafter. Delivering these action points needs coordinated action with policymakers, funders, and service providers.

Conclusion: These action points should be a fundamental part of clinical practice to determine if a change in management is necessary to reduce the risk of exacerbations. Policymakers should use these action points to develop systems and initiatives that reduce the risk of further exacerbations.

Keywords: control, inhaled therapy, primary care, mortality, biomarkers, health policy

\section{Introduction}

Overwhelming evidence highlights the need to reduce the risk of exacerbations, which are common at all stages of chronic obstructive pulmonary disease (COPD) and are among the strongest predictors of future exacerbations and mortality. ${ }^{1-8}$ Exacerbations are common: $49 \%$ of patients experienced at least one exacerbation within the first three years following diagnosis in SPIROMICS. ${ }^{9}$ The overall exacerbation rate increases with severity of airflow obstruction. ${ }^{10}$ 
Exacerbations of any severity cause significant morbidity, including more rapid decline in lung function, reduced quality of life (QoL) and impaired physical activity. ${ }^{2,5,11}$ Moreover, increasing exacerbation frequency has also been associated with higher mortality. ${ }^{1,3}$ Patients who experience more exacerbations after starting maintenance inhaled therapy show a particularly rapid decline in lung function. ${ }^{12}$ The time between exacerbations shortens with more frequent exacerbations. ${ }^{1}$ Exacerbations seem to cluster, which partly accounts for the high hospital readmission rates. ${ }^{13-17}$ Inhospital mortality following an admission for exacerbation can range from $4 \%$ to $25 \% 5$ and each severe exacerbation increases adjusted mortality by $14 \% .{ }^{18}$ COPD also places a significant economic burden on society, with exacerbations responsible for most of the direct medical costs associated with the condition. ${ }^{19-21}$

Despite their clinical and economic importance, exacerbations are often inadequately prevented, poorly defined, underrecognized, underreported, and undertreated. ${ }^{22-32}$ "Clinical inertia" encompasses a failure to assess risk; screen for and manage risk factors and complications; address nonpharmacological factors; and refer appropriately. ${ }^{33}$ Therapeutic inertia, a failure to change therapy when treatment goals are not met is one facet of clinical inertia. ${ }^{33}$ Improving the health system's ability to support healthcare professionals (HCPs) and increasing the influence of specific policy levers (including guidelines, national and regional strategies, incentives and digital system flags) would reduce clinical and therapeutic inertia, although the extent of the improvement requires further research.

Obtaining the views of patients, clinicians managing people with COPD and managers who control budgets and workflows is important to ensure that suggestions to overcome clinical and therapeutic inertia and, in turn, reduce the risk of exacerbations are practicable and clinically relevant. Within this paper, the authors argue that COPD care needs to shift to a paradigm similar to that in cardiology, which focuses on prevention. In COPD, up to $80 \%$ of cases are diagnosed only after the person develops advanced COPD and marked endorgan damage. ${ }^{34}$ This contrasts with cardiovascular diseases (CVD), such as hypertension and dyslipidemia, that are identified by routine assessment. ${ }^{34}$ Hillas et al note the "striking similarity in the catastrophic pathophysiologic cascade" following COPD exacerbations and acute myocardial infarction. Both lead to more symptoms, higher hospitalization rates, lower QoL, impaired exercise capacity and poorer prognosis. ${ }^{4}$

The principles that drove improved primary and secondary prevention of CVD complications - such as addressing risk factors (including smoking cessation ${ }^{35}$ ), early accurate diagnosis, appropriate pharmacotherapy ${ }^{36-38}$ with rapid escalation, rapid referral to other members of the COPD team (eg pulmonary rehabilitation ${ }^{39}$ ) and patient education and self-management ${ }^{40}$ - should reduce exacerbations.

This paper describes four action points (Box 1) developed by a multidisciplinary panel of five active UK expert clinicians managing COPD to help address clinical and

\section{Box I Summary of Actions Points}

\begin{tabular}{|c|}
\hline Action \\
\hline $\begin{array}{l}\text { Overcoming clinical and therapeutic inertia to reduce the risk of exacerbations is central to reducing mortality and morbidity in people with COPD } \\
\text { as well as to avoid further exacerbations and worsening lung function. An experienced HCP, such as a GP or member of the multi-professional } \\
\text { COPD team, should review patients within a month of every exacerbation that requires oral steroids, antibiotics and/or hospitalization. The review } \\
\text { should address modifiable risk factors, optimize non-pharmacological measures, and evaluate pharmacological therapy with a low threshold for } \\
\text { escalation, where appropriate. }\end{array}$ \\
\hline $\begin{array}{l}\text { Presenting to hospital with an exacerbation defines an important window of opportunity to reduce the risk of further exacerbations. In particular, } \\
\text { follow-up by a GP, or member of the multi-professional specialist COPD team in an outpatient setting within one month of discharge }{ }^{49,50} \text { with } \\
\text { a management review and a low threshold for escalating pharmacological treatment, where appropriate, is essential to reduce the risk of } \\
\text { exacerbations and readmissions and improve patient outcomes after hospital discharge. }\end{array}$ \\
\hline $\begin{array}{l}\text { HCPs in all healthcare settings should be able to recognize exacerbations, refer as appropriate and document the episode accurately in medical } \\
\text { records across service boundaries. HCPs should support patients to recognize and report exacerbations. In turn, HCPs should prioritize, review, } \\
\text { and record every exacerbation. }\end{array}$ \\
\hline $\begin{array}{l}\text { HCPs should intervene proactively based on risk assessments, disease activity and any treatable traits at or as soon as possible after diagnosis and } \\
\text { regularly thereafter. The proactive intervention aims to improve COPD trajectory by reducing the risk of exacerbations and ensuring patients } \\
\text { receive appropriate treatment. In the future, HCPs could use biomarkers to tailor treatment more accurately to the patient earlier and ideally from } \\
\text { diagnosis. }\end{array}$ \\
\hline
\end{tabular}


therapeutic inertia and reduce the risk of exacerbations. The action points, which are consensus opinions of the group, are based on the evidence, clinical expertise, and experience, and are intended to be applicable despite changing circumstances (eg, increasing need for virtual healthcare delivery). The paper also highlights areas where further evidence is needed.

\section{Act on Exacerbations: Review and Reduce Action Point}

Overcoming clinical and therapeutic inertia to reduce the risk of exacerbations is central to reducing mortality and morbidity in people with COPD as well as to avoid further exacerbations and worsening lung function. An experienced HCP, such as a GP or member of the multi-professional COPD team, should review patients within a month of every exacerbation that requires oral steroids, antibiotics and/or hospitalization. The review should address modifiable risk factors, optimize non-pharmacological measures, and evaluate pharmacological therapy with a low threshold for escalation, where appropriate.

The GOLD recommendations cover follow-up after hospitalization (severe exacerbation). ${ }^{19}$ It is less clear, however, whether the GOLD recommendations apply after moderate events. Despite the significant impact of exacerbations, many patients do not receive any on-going preventative treatment despite experiencing symptoms or having a history of exacerbations and in many cases COPD management often does not follow treatment guidelines. $^{29-32}$ For instance, many people diagnosed with COPD are not prescribed maintenance inhaled therapy, despite evidence that this reduces the exacerbation risk in some patients. ${ }^{12,41}$ Of those receiving treatment, up to three-quarters of people that experience two or more exacerbations continue to be undertreated according to GOLD recommendations. ${ }^{42}$ Halpin et al reported that only between $33 \%$ and $60 \%$ of patients are treated appropriately according to GOLD recommendations. ${ }^{42}$

To reduce the risk of further exacerbations, an experienced HCP, such as a GP or member of the multiprofessional COPD team should review pharmacological and non-pharmacological (eg, smoking cessation, influenza and pneumococcal vaccinations and pulmonary rehabilitation ${ }^{43}$ ) management after each exacerbation that either requires oral steroids or antibiotics, or hospitalization. This is aligned with the recent patient charter on COPD. ${ }^{44}$
Accessing smoking cessation services, vaccinations and pulmonary rehabilitation is often difficult, ${ }^{45}$ which may hinder attempts to reduce the risk of further exacerbations. If, after excluding these factors, the review reveals an inadequate treatment response, HCPs should have a low threshold for escalating pharmacological therapy, in line with the GOLD strategy and local guidelines, to reduce the risk of further exacerbations. ${ }^{19,46}$ If still not successful, HCPs should consider referral to secondary care.

COPD patients should receive a written, evidencebased, and individualized management plan at diagnosis that is reviewed at each appointment, to enable proactive treatment of an exacerbation, rather than waiting until respiratory health worsens. The management plan should stress the importance of contacting the GP and receiving a review within a month of every exacerbation to reduce the risk of further exacerbations.

Rescue packs should be considered for appropriate patients able to self-manage. A rescue pack should consist of an antibiotic, steroid, or both that patients keep at home, ${ }^{47}$ with clear instructions about use and when and how to seek help. The COPD management plan should clearly inform the patient when to use the pack $^{48}$ and stress the importance of alerting the HCP that they have used the pack to ensure that the exacerbation triggers a treatment review. Rescue packs should not be available on repeat prescription and should be reviewed carefully after every exacerbation. Follow-up is, however, not routinely performed. This potentially leads to multiple and unnecessary use. Moreover, studies are needed to determine the clinical benefit of rescue packs in real-world clinical practice. Currently, our experience is that followup is not routine, which can lead to potentially multiple unnecessary uses of rescue medication.

Patients with stable COPD should be reviewed at least annually to ensure correct inhaler technique, concordance with pharmacological and non-pharmacological interventions, and to evaluate whether the COPD is stable, worsening or progressing. Patients do not necessarily report exacerbations to $\mathrm{HCPs},{ }^{22-27}$ underscoring the importance of a comprehensive history taking and risk assessment (see below). Symptomatic worsening, deteriorating lung function or poorer QoL reported at routine reviews, together with a history of exacerbations, may indicate an increased exacerbation risk. Further studies are needed to confirm this empirical observation. Additional research is also needed to ascertain if there are objective criteria for stepping down treatment in COPD or whether patients who have not 
experienced an exacerbation requiring oral steroids or antibiotics or hospitalization for at least one year should remain on their current treatment.

\section{Act on Hospital Discharge and Follow-Up \\ Action Point}

Presenting to hospital with an exacerbation defines an important window of opportunity to reduce the risk of further exacerbations. In particular, follow-up by a GP, or member of the multi-professional specialist COPD team in an outpatient setting within one month of discharge ${ }^{49,50}$ with a management review and a low threshold for escalating pharmacological treatment, where appropriate, is essential to reduce the risk of exacerbations and readmissions and improve patient outcomes after hospital discharge.

Readmissions following discharge from hospital after an exacerbation are common. ${ }^{14-17}$ The National Asthma and COPD Audit Program in England and Wales reported that during $2017 / 18,23.9 \%$ and $43.2 \%$ of 53,903 index admissions with COPD were readmitted at least once within 30 and 90 days of the index discharge date, respectively. COPD was the most common cause for readmission, accounting for $39.5 \%$ and $46.8 \%$ of readmissions within 30 and 90 days, respectively. ${ }^{17}$ Early clinic follow-up after an exacerbation appears to reduce the risk of readmission due to COPD exacerbations. ${ }^{5,49,50}$ Exacerbations cluster, ${ }^{13}$ so follow-up within one month of every exacerbation offers the opportunity to optimize treatment to reduce the risk of exacerbations. Failure to offer early clinic follow-up after an exacerbation can, therefore, undermine attempts to reduce the risk of further exacerbations.

Improved implementation of evidence-based interventions could avoid almost a third of COPD admissions. ${ }^{51}$ A care bundle, which consolidates a package of evidencebased interventions, should include a review of medication and inhaler use; provision of a written self-management plan; offering access and referral for smoking cessation; assessing suitability for pulmonary rehabilitation; and arranging a follow-up call within 72 hours of discharge. ${ }^{47}$ Most care bundles do not, however, encompass co-morbidities and medication choice.

HCPs value care bundles. ${ }^{52}$ According to the 2018/19 clinical audit in the UK, however, only $73.8 \%$ of patients admitted to hospital with an exacerbation received a care bundle on discharge. ${ }^{53}$ There is some evidence that emergency department readmissions were 37\% lower among patients who received care bundles. ${ }^{52}$ Implementation of care bundles can, however, be challenging. In addition, further studies need to assess the impact of care bundles on COPD or all-cause re-admission rates, mortality, length of stay, total number of bed-days, resource utilization, National Health Service (NHS) secondary care costs and costeffectiveness. ${ }^{52}$ Nevertheless, HCPs and systems should consider implementing a care bundle to ensure the best clinical outcome for patients admitted with exacerbations. ${ }^{47,51,54}$

\section{Act on Recognition, Reporting and Recording of Every Exacerbation Action Point}

HCPs in all healthcare settings should be able to recognize exacerbations, refer as appropriate and document the episode accurately in medical records across service boundaries. HCPs should support patients to recognize and report exacerbations. In turn, HCPs should prioritize, review, and record every exacerbation.

Exacerbations of any severity cause significant morbidity, including a more rapid decline in lung function, consequently reducing QoL and physical activity as well as increasing the risk of further exacerbations. ${ }^{1-7,11}$ Yet patients report only between $15 \%$ and $60 \%$ of exacerbations to $\mathrm{HCPs}^{22-28}$ Unreported exacerbations can undermine health. ${ }^{19,26-28}$ One study reported that $52 \%$ and $43 \%$ of those with reported and unreported exacerbations experienced a clinically important decline in health status. ${ }^{28}$ HCPs need to ensure that patients can recognize the symptoms of an exacerbation and know when to seek advice from a HCP. ${ }^{19}$

In people with COPD, structured education reduces the need for hospital care, enhances QoL and disease knowledge, and improves concordance with treatment. ${ }^{55,56}$ Education about COPD self-management should be explicit, individualized, and offered continuously. ${ }^{55}$ However, despite being recommended in management guidelines, only about $40 \%$ of COPD patients have self-management plans, ${ }^{56}$ which hinders attempts to reduce the risk of exacerbations.

HCPs should ensure that patients receive individualized education about recognizing exacerbations and the management steps, including when to seek medical assistance and addressing lifestyle factors that might contribute to the exacerbation. Treatment goals should encompass exacerbation reduction. HCPs should ensure that patients appreciate the importance of an HCP review after every exacerbation to 
address deteriorating lung function and reduce the risk of further exacerbations.

Patients with exacerbations can present in nonrespiratory settings. As many COPD patients have comorbidities and exacerbations can be misdiagnosed, HCPs in all healthcare settings should be able to recognize acute exacerbations and be familiar with local referral pathways.

\section{Act on Predictors of Risk for Exacerbations \\ Action Point}

HCPs should intervene proactively based on risk assessments, disease activity and any treatable traits at or as soon as possible after diagnosis and regularly thereafter. The proactive intervention aims to improve COPD trajectory by reducing the risk of exacerbations and ensuring patients receive appropriate treatment. In the future, $\mathrm{HCPs}$ could use biomarkers to tailor treatment more accurately to the patient earlier and ideally from diagnosis.

Individualized intervention as soon as possible after diagnosis is essential. HCPs should, therefore, intervene proactively based on risk assessments, disease activity and any treatable traits (a therapeutic target identified by a clinical or pathophysiological characteristic ${ }^{57}$ ) at, or as soon as possible after, diagnosis and regularly thereafter.

Numerous factors increase exacerbation risk, including COPD severity, previous exacerbations, increasing Medical Research Council (MRC) dyspnea score and airflow limitation $\left(\mathrm{FEV}_{1}\right)$ and comorbidities. ${ }^{7,58}$ In addition, several characteristics are associated with increased COPD-related mortality including age; dyspnea; higher body mass index (BMI); loss of lean (muscle) mass; carbon monoxide transfer factor; arterial oxygen partial pressure and $\mathrm{FEV}_{1}{ }^{43,59-61}$ Many of these are non-modifiable, but offer an opportunity to discuss improving other aspects of management. Despite awareness of the numerous risk factors, further research is needed to determine the relevant contribution of biomarkers in predicting outcomes and reducing exacerbations.

In people with $\mathrm{COPD}, \mathrm{FEV}_{1}$ predicts outcomes, including mortality and hospitalizations, and can trigger consideration of surgical procedures at a population level. ${ }^{62}$ However, $\mathrm{FEV}_{1}$ shows weaker prognostic value for individual patients and does not necessarily correlate with symptoms, QoL or exacerbation frequency. ${ }^{62}$ Therefore, used alone, $\mathrm{FEV}_{1}$ cannot determine the optimal treatment to reduce the exacerbation risk in particular patients. ${ }^{62}$

Multiple studies report that elevated blood eosinophil can predict a good response to inhaled corticosteroids (ICS). ${ }^{19,43,63,64}$ GOLD suggests that blood eosinophil counts less than 100 cells $/ \mu \mathrm{L}$ identify COPD patients with a low likelihood of benefiting from ICS. Blood eosinophil counts more than 300 cells/ $\mu \mathrm{L}$ identify COPD patients with the greatest likelihood of benefiting from ICS. Measuring blood eosinophil counts can, therefore, help HCPs estimate the benefit of adding ICS to regular bronchodilator treatment. ${ }^{19}$.

Composite indices can facilitate assessment of exacerbation risk in routine clinical practice. The Dyspnoea, Obstruction, Smoking, Exacerbation (DOSE) index, for example, offers a practical risk assessment that combines the MRC dyspnea scale, $\mathrm{FEV}_{1}$ as percentage of the predicted value, smoking status, and exacerbation rate during the previous year. The total score ranges from 0 to 8 , with higher scores reflecting more severe COPD. ${ }^{65}$ The Body mass index, Obstruction, Dyspnea and Exacerbations (BODEx) index offers another practical risk assessment. The original Body mass index, Obstruction, Dyspnoea and Exercise (BODE) index included BMI, airflow obstruction, dyspnea, and exercise capacity. The BODEx index replaces exercise capacity with severe exacerbations and predicts mortality risk. ${ }^{18}$

Further studies should examine the role of treatment guided by lung function on COPD trajectory and exacerbation rates. In the meantime, HCPs should have a low threshold for pharmacological escalation, where appropriate, to reduce the risk of exacerbations if patients show declining lung function on repeated $\mathrm{FEV}_{1}$ tests. Studies should determine the optimal frequency of routine lung function monitoring. Until these studies are available, HCPs should monitor $\mathrm{FEV}_{1}$ at least annually and when clinically indicated (eg, after changing therapy).

\section{Summary}

Overwhelming evidence highlights the need to reduce the risk of exacerbations, which are common at all COPD stages and among the strongest risk factors for future exacerbations. ${ }^{1-7}$ World-wide 328.6 million people live with COPD. ${ }^{66}$ About half of these will experience at least one exacerbation during a three-year follow-up. ${ }^{9}$ Despite the burden of illness, exacerbations are often under-recognized, underreported and undertreated. There is a need to urgently review management of exacerbations in clinical practice to reduce the risk of further exacerbations. This paper proposes action points (Box 1), 
developed by a multidisciplinary group of active expert clinicians managing COPD, to reduce exacerbation risk, aligned with the recent COPD patient charter. ${ }^{44}$ These action points should be a fundamental part of clinical practice to determine if a change in management is necessary to reduce the risk of exacerbations.

To deliver these action points, we need appropriate health systems and standards in place to support clinicians. We need coordinated action with policymakers, funders, and service providers to address factors that hinder optimal reductions in the exacerbation rate, which may lower hospitalizations and healthcare costs. Improved implementation of evidence-based interventions could, for example, avoid almost a third of COPD admissions. ${ }^{51}$ Local management protocols should, therefore, stress the importance of focusing on treatment goals and managing and recording each exacerbation as part of a coordinated response across healthcare settings to reduce the risk of further exacerbations. Policymakers should use these action points to develop systems and initiatives that reduce the risk of further exacerbations.

\section{Acknowledgments}

ENGINE MHP, provided medical writing assistance and provided a 'secretariat' role to the multidisciplinary National Working group, both funded by AstraZeneca, which reviewed the manuscript and made suggestions for the authors to consider.

\section{Author Contributions}

All authors made a significant contribution to the work reported, whether that is in the conception, study design, execution, acquisition of data, analysis and interpretation, or in all these areas; took part in drafting, revising or critically reviewing the article; gave final approval of the version to be published; have agreed on the journal to which the article has been submitted; and agree to be accountable for all aspects of the work.

\section{Funding}

AstraZeneca funded medical writing assistance and the "secretariat" role to the multidisciplinary National Working group.

\section{Disclosure}

Claire Adams: Honoraria and speaker fees from AstraZeneca; Boehringer Ingelheim; Chiesi; Napp; GlaxoSmithKline; Mona Bafadhel: Research Grants from AstraZeneca. Educational Talks with AstraZeneca, Cipla and GlaxoSmithKline. Scientific Advisor to ProAxsis and Albus Health and is supported by the National Institute for Health Research (NIHR) Oxford Biomedical Research Centre (BRC). Steve Holmes: Honoraria and speaker fees in the last 2 years from AstraZeneca, Boehringer Ingelheim, Chiesi, GlaxoSmithKline, Mylan, Napp, Roche, Teva, Trudell, Viatris. John R Hurst: Support to attend meetings, and personal payment and payment to his employer (UCL) for educational and advisory work from pharmaceutical companies that make medicines to treat COPD including AstraZeneca, Chiesi and Boehringer Ingelheim. Dave Singh: Grants and personal fees from Aerogen, AstraZeneca, CSL Behring, Boehringer Ingelheim, Chiesi, Cipla, Epiendo, Genentech, GlaxoSmithKline, Glenmark, Gossamerbio, Kinaset, Menarini, Novartis, Pulmatrix, Sanofi, Synairgen, Teva, Theravance and Verona, and is supported by the National Institute for Health Research (NIHR) Manchester Biomedical Research Centre (BRC). The authors report no other conflicts of interest relevant to this work.

\section{References}

1. Suissa S, Dell'Aniello S, Ernst P. Long-term natural history of chronic obstructive pulmonary disease: severe exacerbations and mortality. Thorax. 2012;67(11):957-963. doi:10.1136/thoraxjnl2011-201518

2. Hurst JR, Vestbo J, Anzueto A, et al. Susceptibility to exacerbation in chronic obstructive pulmonary disease. NEJM. 2010;363 (12):1128-1138. doi:10.1056/NEJMoa0909883

3. Rothnie KJ, Müllerová H, Smeeth L, Quint JK. Natural history of chronic obstructive pulmonary disease exacerbations in a general practice-based population with chronic obstructive pulmonary disease. Am J Respir Crit Care Med. 2018;198(4):464-471. doi:10.1164/rccm.201710-2029OC

4. Hillas G, Perlikos F, Tzanakis N. Acute exacerbation of COPD: is it the "stroke of the lungs"? Int J Chron Obstruct Pulmon Dis. 2016;11:1579-1586. doi:10.2147/COPD.S106160

5. Ko FW, Chan KP, Hui DS, et al. Acute exacerbation of COPD. Respirology. 2016;21(7):1152-1165. doi:10.1111/resp.12780

6. Kim JK, Lee SH, Lee BH, et al. Factors associated with exacerbation in mild- to-moderate COPD patients. Int J Chron Obstruct Pulmon Dis. 2016;11:1327-1333. doi:10.2147/COPD.S105583

7. Müllerová H, Shukla A, Hawkins A, Quint J. Risk factors for acute exacerbations of COPD in a primary care population: a retrospective observational cohort study. BMJ Open. 2014;4(12):e006171. doi:10.1136/bmjopen-2014-006171

8. Andreas S, Taube C. Inhaled therapy reduces COPD mortality. ERJ Open Res. 2020;6(4):00634-02020. doi:10.1183/23120541.006342020

9. Han MK, Quibrera PM, Carretta EE, et al. Frequency of exacerbations in patients with chronic obstructive pulmonary disease: an analysis of the SPIROMICS cohort. Lancet Respir Med. 2017;5 (8):619-626. doi:10.1016/s2213-2600(17)30207-2

10. Merinopoulou E, Raluy-Callado M, Ramagopalan S, MacLachlan S, Khalid JM. COPD exacerbations by disease severity in England. Int J Chron Obstruct Pulmon Dis. 2016;11:697-709. doi:10.2147/ copd.s 100250 
11. Donaldson GC, Seemungal TA, Bhowmik A, Wedzicha JA. Relationship between exacerbation frequency and lung function decline in chronic obstructive pulmonary disease. Thorax. 2002;57 (10):847-852. doi:10.1136/thorax.57.10.847

12. Kerkhof M, Voorham J, Dorinsky P, et al. The long-term burden of COPD exacerbations during maintenance therapy and lung function decline. Int J Chron Obstruct Pulmon Dis. 2020;15:1909-1918. doi:10.2147/copd.s253812

13. Hurst JR, Donaldson GC, Quint JK, Goldring JJP, Baghai-Ravary R, Wedzicha JA. Temporal clustering of exacerbations in chronic obstructive pulmonary disease. Am J Respir Crit Care Med. 2009;179(5):369-374. doi:10.1164/rccm.200807-1067OC

14. Baker CL, Zou KH, Su J. Risk assessment of readmissions following an initial COPD-related hospitalization. Int J Chron Obstruct Pulmon Dis. 2013;8:551-559. doi:10.2147/copd.s51507

15. Milne RJ, Beasley R. Hospital admissions for chronic obstructive pulmonary disease in New Zealand. $N Z$ Med J. 2015;128 (1408):23-35.

16. Harries TH, Thornton H, Crichton S, Schofield P, Gilkes A, White PT. Hospital readmissions for COPD: a retrospective longitudinal study. NPJ Prim Care Respir Med. 2017;27(1):31. doi:10.1038/s41533-017-0028-8

17. Hurst J, Shanahan L, Imoedemhe E, et al.; National Asthma and Chronic Obstructive Pulmonary Disease Audit Programme (NACAP). Outcomes of patients included in the 2017/18 COPD clinical audit (patients with COPD exacerbations discharged from acute hospitals in England and Wales between September 2017 and September 2018). Audit report. London: Royal College of Physicians; 2020. Available from: https:/www.nacap.org.uk/nacap/ welcome.nsf/vwFiles/NACAP-COPD-SC-202007a/\$File/NACAP COPD_SC_Outcomes_2017-18_Report 290620.pdf?openelement. Accessed September 17, 2020

18. Soler-Cataluña JJ, Martínez-García MÁ, Sánchez LS, Tordera MP, Sánchez PR. Severe exacerbations and BODE index: two independent risk factors for death in male COPD patients. Resp Med. 2009;103(5):692-699. doi:10.1016/j.rmed.2008.12.005

19. Global Initiative for Chronic Obstructive Lung Disease. 2021 global strategy for prevention, diagnosis and management of COPD. Available from: https://goldcopd.org/2021-gold-reports/. Accessed December 18, 2020.

20. Chen X, Wang N, Chen Y, Xiao T, Fu C, Xu B. Costs of chronic obstructive pulmonary disease in urban areas of China: a cross-sectional study in four cities. Int J Chron Obstruct Pulmon Dis. 2016;11:2625-2632. doi:10.2147/COPD.S118523

21. Nishimura S, Zaher C. Cost impact of COPD in Japan: opportunities and challenges? Respirology. 2004;9(4):466-473. doi:10.1111/j.14401843.2004.00617.x

22. Seemungal TA, Donaldson GC, Paul EA, Bestall JC, Jeffries DJ, Wedzicha JA. Effect of exacerbation on quality of life in patients with chronic obstructive pulmonary disease. Am J Respir Crit Care Med. 1998;157(5 Pt 1):1418-1422. doi:10.1164/ajrccm.157.5.9709032

23. Vijayasaratha K, Stockley RA. Reported and unreported exacerbations of COPD: analysis by diary cards. Chest. 2008;133(1):34-41. doi:10.1378/chest.07-1692

24. Wilkinson TMA, Donaldson GC, Hurst JR, Seemungal TAR, Wedzicha JA. Early therapy improves outcomes of exacerbations of chronic obstructive pulmonary disease. Am J Respir Crit Care Med. 2004;169(12):1298-1303. doi:10.1164/rccm.200310-1443OC

25. Leidy NK, Murray LT, Jones P, Sethi S. Performance of the EXAcerbations of chronic pulmonary disease tool patient-reported outcome measure in three clinical trials of chronic obstructive pulmonary disease. Ann Am Thorac Soc. 2014;11(3):316-325. doi:10.1513/AnnalsATS.201309-305OC

26. Jones PW, Lamarca R, Chuecos F, et al. Characterisation and impact of reported and unreported exacerbations: results from ATTAIN. Eur Respir J. 2014;44(5):1156-1165. doi:10.1183/09031936.00038814
27. Xu W, Collet JP, Shapiro S, et al. Negative impacts of unreported COPD exacerbations on health-related quality of life at 1 year. Eur Resp J. 2010;35(5):1022-1030. doi:10.1183/09031936.00079409

28. Langsetmo L, Platt RW, Ernst P, Bourbeau J. Underreporting exacerbation of chronic obstructive pulmonary disease in a longitudinal cohort. Am J Respir Crit Care Med. 2008;177(4):396-401. doi:10.1164/rccm.200708-12900C

29. Price D, West D, Brusselle G, et al. Management of COPD in the UK primary-care setting: an analysis of real-life prescribing patterns. Int J Chron Obstruct Pulmon Dis. 2014;9:889-904. doi:10.2147/ COPD.S62750

30. Albitar HAH, Iyer VN. Adherence to Global Initiative for Chronic Obstructive Lung Disease guidelines in the real world: current understanding, barriers, and solutions. Curr Opin Pulm Med. 2020;26 (2):149-154. doi:10.1097/MCP.0000000000000655

31. Worth H, Buhl R, Criee CP, Kardos P, Mailander C, Vogelmeier C. The 'real-life' COPD patient in Germany: the DACCORD study. Respir Med. 2016;111:64-71. doi:10.1016/j.rmed.2015.12.010

32. Tabyshova A, Hurst JR, Soriano JB. Gaps in COPD guidelines of low- and middle-income countries: a systematic scoping review. Chest. 2021;159(2):575-584. doi:10.1016/j.chest.2020.09.260

33. Khunti K, Davies MJ. Clinical inertia-time to reappraise the terminology? Prim Care Diabetes. 2017;11(2):105-106. doi:10.1016/j.pcd.2017.01.007

34. Price DB, Yawn BP, Jones RCM. Improving the differential diagnosis of chronic obstructive pulmonary disease in primary care. Mayo Clin Proc. 2010;85(12):1122-1129. doi:10.4065/mcp.2010.0389

35. van Eerd EA, van der Meer RM, van Schayck OC, Kotz D. Smoking cessation for people with chronic obstructive pulmonary disease. Cochrane Database Syst Rev. 2016;2016(8):Cd010744. doi:10.1002/ 14651858.CD010744.pub2

36. Maqsood U, Ho TN, Palmer $\mathrm{K}$, et al. Once daily long-acting beta2-agonists and long-acting muscarinic antagonists in a combined inhaler versus placebo for chronic obstructive pulmonary disease. Cochrane Database Syst Rev. 2019;3(3):Cd012930. doi:10.1002/14651858.CD012930.pub2

37. Ni H, Moe S, Soe Z, Myint KT, Viswanathan KN. Combined Aclidinium bromide and long-acting beta2-agonist for chronic obstructive pulmonary disease (COPD). Cochrane Database Syst Rev. 2018;12(12):Cd011594. doi:10.1002/14651858.CD011594.pub2

38. Sliwka A, Jankowski M, Gross-Sondej I, Storman M, Nowobilski R, Bala MM. Once-daily long-acting beta2-agonists/inhaled corticosteroids combined inhalers versus inhaled long-acting muscarinic antagonists for people with chronic obstructive pulmonary disease. Cochrane Database Syst Rev. 2018;8(8):Cd012355. doi:10.1002/ 14651858.CD012355.pub2

39. McCarthy B, Casey D, Devane D, Murphy K, Murphy E, Lacasse Y. Pulmonary rehabilitation for chronic obstructive pulmonary disease. Cochrane Database Syst Rev. 2015;2:Cd003793. doi:10.1002/ 14651858.CD003793.pub3

40. Zwerink M, Brusse-Keizer M, van der Valk PD, et al. Self management for patients with chronic obstructive pulmonary disease. Cochrane Database Syst Rev. 2014;2014(3):Cd002990. doi:10.1002/ 14651858.CD002990.pub3

41. Make B, Dutro MP, Paulose-Ram R, Marton JP, Mapel DW. Undertreatment of COPD: a retrospective analysis of US managed care and medicare patients. Int J Chron Obstruct Pulmon Dis. 2012;7:1-9. doi:10.2147/COPD.S27032

42. Halpin DMG, de Jong HJ, Carter V, Skinner D, Price D. Distribution, temporal stability and appropriateness of therapy of patients with COPD in the UK in relation to GOLD 2019. EClinicalMedicine. 2019;14:32-41. doi:10.1016/j.eclinm.2019.0 7.003

43. Riley CM, Sciurba FC. Diagnosis and outpatient management of chronic obstructive pulmonary disease: a review. JAMA. 2019;321 (8):786-797. doi:10.1001/jama.2019.0131 
44. Hurst JR, Winders $\mathrm{T}$, Worth $\mathrm{H}$, et al. A patient charter for chronic obstructive pulmonary disease. Adv Ther. 2021;38(1):11-23. doi:10.1007/s12325-020-01577-7

45. Johnston KN, Young M, Grimmer-Somers KA, Antic R, Frith PA. Why are some evidence-based care recommendations in chronic obstructive pulmonary disease better implemented than others? Perspectives of medical practitioners. Int J Chron Obstruct Pulmon Dis. 2011;6:659-667. doi:10.2147/COPD.S26581

46. National Institute for Clinical Excellence. Chronic obstructive pulmonary disease; 2018. Available from: http://www.nice.org.uk/nice media/live/13029/49397/49397.pdf. Accessed August 17, 2020.

47. British Thoracic Society. BTS chronic obstructive pulmonary disease (COPD) discharge care bundle. Available from: https://www.britthoracic.org.uk/quality-improvement/clinical-resources/copdspirometry/. Accessed August 31, 2020.

48. Davies F, Risør MB, Melbye H, et al. Primary and secondary care clinicians' views on self-treatment of COPD exacerbations: a multinational qualitative study. Patient Educ Couns. 2014;96 (2):256-263. doi:10.1016/j.pec.2014.05.011

49. Gavish R, Levy A, Dekel OK, Karp E, Maimon N. The association between hospital readmission and pulmonologist follow-up visits in patients with COPD. Chest. 2015;148(2):375-381. doi:10.1378/ chest.14-1453

50. Sharma G, Kuo YF, Freeman JL, Zhang DD, Goodwin JS. Outpatient follow-up visit and 30-day emergency department visit and readmission in patients hospitalized for chronic obstructive pulmonary disease. Arch Intern Med. 2010;170(18):1664-1670. doi:10.1001/ archinternmed.2010.345

51. Gómez-Angelats E, Sánchez C. Care bundles after discharging patients with chronic obstructive pulmonary disease exacerbation from the emergency department. Med Sci. 2018;6(3). doi:10.3390/ medsci6030063

52. Morton K, Sanderson E, Dixon P, et al. Health Services and Delivery Research. Care bundles to reduce re-admissions for patients with chronic obstructive pulmonary disease: a mixed-methods study. Southampton (UK): NIHR Journals Library; 2019.

53. Hurst J, Legg M, Shanahan L, et al.; National Asthma and Chronic Obstructive Pulmonary Disease Audit Programme (NACAP). COPD clinical audit 2018/19 (people with COPD exacerbations discharged from acute hospitals in England, Scotland and Wales between September 2018 and 2019). Clinical audit report London: Royal College of Physicians; 2020. Available from: https://www.rcplon don.ac.uk/projects/national-asthma-and-copd-audit-programme-nacap -secondary-care-workstream-copd. Accessed August 31, 2020.

54. Hopkinson NS, Englebretsen C, Cooley N, et al. Designing and implementing a COPD discharge care bundle. Thorax. 2012;67 (1):90-92. doi:10.1136/thoraxjnl-2011-200233
55. Khdour MR, Kidney JC, Smyth BM, McElnay JC. Clinical pharmacy-led disease and medicine management programme for patients with COPD. Br J Clin Pharmacol. 2009;68(4):588-598. doi:10.1111/j.1365-2125.2009.03493.x

56. Khan A, Dickens AP, Adab P, Jordan RE. Self-management behaviour and support among primary care COPD patients: cross-sectional analysis of data from the Birmingham Chronic Obstructive Pulmonary Disease Cohort. NPJ Prim Care Respir Med. 2017;27(1):46. doi:10.1038/s41533-017-0046-6

57. McDonald VM, Osadnik CR, Gibson PG. Treatable traits in acute exacerbations of chronic airway diseases. Chron Respir Dis. 2019;16:1479973119867954. doi:10.1177/1479973119867954

58. Mantero M, Rogliani P, Di Pasquale M, et al. Acute exacerbations of COPD: risk factors for failure and relapse. Int J Chron Obstruct Pulmon Dis. 2017;12:2687-2693. doi:10.2147/COPD.S145253

59. Boutou AK, Shrikrishna D, Tanner RJ, et al. Lung function indices for predicting mortality in COPD. Eur Respir J. 2013;42(3):616-625. doi: $10.1183 / 09031936.00146012$

60. Chan SMH, Selemidis S, Bozinovski S, Vlahos R. Pathobiological mechanisms underlying metabolic syndrome (MetS) in chronic obstructive pulmonary disease (COPD): clinical significance and therapeutic strategies. Pharmacol Ther. 2019;198:160-188. doi:10.1016/j.pharmthera.2019.02.013

61. Barreiro E, Jaitovich A. Muscle atrophy in chronic obstructive pulmonary disease: molecular basis and potential therapeutic targets. J Thorac Dis. 2018;10(Suppl 12):S1415-s1424. doi:10.21037/jtd.2018.04.168

62. Vogelmeier CF, Román-Rodríguez M, Singh D, Han MK, RodríguezRoisin R, Ferguson GT. Goals of COPD treatment: focus on symptoms and exacerbations. Respir Med. 2020;166:105938. doi:10.1016/ j.rmed.2020.105938

63. Bafadhel M, Peterson S, De Blas MA, et al. Predictors of exacerbation risk and response to budesonide in patients with chronic obstructive pulmonary disease: a post-hoc analysis of three randomised trials. Lancet Respir Med. 2018;6(2):117-126. doi:10.1016/s2213-2600(18)30006-7

64. Kerkhof M, Voorham J, Dorinsky P, et al. Association between COPD exacerbations and lung function decline during maintenance therapy. Thorax. 2020;75(9):744-753. doi:10.1136/thoraxjnl-2019-214457

65. Sundh J, Janson C, Lisspers K, Ställberg B, Montgomery S. The Dyspnoea, Obstruction, Smoking, Exacerbation (DOSE) index is predictive of mortality in COPD. Prim Care Respir J. 2012;21 (3):295-301. doi:10.4104/pcrj.2012.00054

66. Vos T, Flaxman AD, Naghavi M, et al. Years lived with disability (YLDs) for 1160 sequelae of 289 diseases and injuries 1990-2010: a systematic analysis for the Global Burden of Disease Study 2010. Lancet. 2012;380(9859):2163-2196. doi:10.1016/s0140-6736(12) 61729-2

\section{Publish your work in this journal}

The International Journal of COPD is an international, peer-reviewed journal of therapeutics and pharmacology focusing on concise rapid reporting of clinical studies and reviews in COPD. Special focus is given to the pathophysiological processes underlying the disease, intervention programs, patient focused education, and self management protocols. This journal is indexed on PubMed Central, MedLine and CAS. The manuscript management system is completely online and includes a very quick and fair peer-review system, which is all easy to use. Visit http://www.dovepress.com/testimonials.php to read real quotes from published authors. 